\title{
$\mathrm{ERCP}$ 를 시작하는 의사가 알아야 할 보험청구
}

연세대학교 원주의과대학 내과학교실

이경주

\section{Knowledge of Insurance Claim for ERCP Beginner}

\author{
Kyong Joo Lee \\ Department of Internal Medicine, Yonsei University Wonju College of Medicine, Wonju, Korea
}

In performing endoscopic retrograde cholangiopancreatography (ERCP), doctors should know the details of insurance claims. The fee of ERCP will be charged separately by the treatment fee and the material costs, and should be charged according to the insurance claims to avoid any disadvantages later. Insurance claims for ERCP are often changed, so doctors have to notice the changes and apply them. During the procedure, it is important to properly record the photograph as a basis, and to keep a good description of the procedure and materials used on the reading sheet. After the procedure, it is necessary to double check the prescription and verify that the insurance claim has been properly filed.

Korean J Pancreas Biliary Tract 2021;26(2):85-88

Keywords: Insurance claim, Cholangiopancreatography, endoscopic retrograde, Treatment cost, Material cost

\begin{abstract}
Received Nov. 30, 2020
Revised Apr. 21, 2021

Accepted Apr. 23, 2021
\end{abstract}

\section{Corresponding author: Kyong Joo Lee} Department of Internal Medicine, Yonsei University Wonju College of Medicine, 20 Ilsan-ro, Wonju 26426, Korea

Tel: +82-33-741-0507 Fax. +82-33-741-1228

E-mail; smild123@yonsei.ac.kr

ORCID: https://orcid.org/0000-0002-9175-9164
This is an Open Access article distributed under the terms of the Creative Commons Attribution Non-Commercial License (http:/ creativecommons.org/licenses/by-nc/3.0/) which permits unrestricted non-commercial use, distribution, and reproduction in any medium, provided the original work is properly cited.

Copyright @ 2021 by The Korean Journal of Pancreas and Biliary Tract

\section{서 론}

건강보험심사평가원(심평원) 자료에 따르면 해마다 내시경역행담췌관조영술 (endoscopic retrograde cholangiopancreatography, ERCP) 건수는 늘고 있다. ${ }^{1,2}$ 2013년부터 2017년 심평원 기록을 살펴보면, 특히 80세 이상에서 $\mathrm{ERCP}$ 건수가 늘었다. $\mathrm{ERCP}$ 술기가 점점 발전하고 보험고시도 새롭게 변경되면서 보험고시대로 신청을 안 하거나 신청이 누락되는 경우가 있으며, 이런 경우 시술에 대한 보상을 제대로 받을 수가 없다. 따라서, ERCP 시술을 하는 의사는 보험고시를 잘 숙지하고 시술에 임할 필요가 있다. 심평원 요양기관업무포탈(http://biz.hira.or.kr)에서 심사 기준을 모두 살펴볼 수 있으며 대한췌장담도학회 홈페이지 (https://www.kpba.kr)에서도 주요 고시는 보험자료에 정리되어 있다. 본고에서는 $\mathrm{ERCP}$ 를 처음 시작하는 의사가 반드시 알아야 할 보험청구에 대해서 살펴보고자 한다.

\section{본 론}

$\mathrm{ERCP}$ 를 시행한 후 보험청구를 하기 위해 처방을 내게 되며 보통 행위료와 재료비로 나누어서 청구를 하게 된다. 행위료는 어떤 시술을 하였는지에 대해 청구하고 재료비는 그 행위를 
하기 위해 사용한 재료에 대해 청구를 하게 된다. 예를 들어, 총담관결석을 제거하기 위해 $\mathrm{ERCP}$ 를 하였을 때, 행위료는 담석제거술이 되고, 이때 사용한 파필로톰(papillotome), 바스켓(basket catheter), 풍선도관(balloon catheter) 등은 재료비로 청구하게 된다. 행위료와 재료비로 나누어서 청구하는 방법을 알아보겠다.

\section{1. 행위료}

기본적으로 2 가지 이상의 시술을 동시에 실시한 경우에는 주된 시술의 소정 점수로 $100 \%$ 산정한다(Table 1). 앞서 예를 든 총담관결석 제거술의 경우, 일반적으로 유두괄약근절개술 (endoscopic sphincterotomy, EST)을 한 후 필요에 따라 내시경적 담관 협착확장술을 하고 담석제거술을 하게 되는데, 3 가지 시술을 하였지만 이 중 주된 시술 하나에 대해서만 청구를 하는 것이다. 통상적으로 가장 중요한 비중을 차지한 시술을 주시술로 결정하여 청구를 한다.

기본적으로 2 가지 이상의 시술을 동시에 실시한 경우에는 주된 시술의 소정 점수로 $100 \%$ 산정한다(Table 1). 앞서 예를 든 총담관결석 제거술의 경우, 일반적으로 유두괄약근절개술 (endoscopic sphincterotomy, EST)을 한 후에 필요에 따라 내시경적 담관 협착확장술을 하고 담석제거술을 하게 되는데, 3 가지 시술을 하였지만 이 중 주된 시술 하나에 대해서만 청구를 하는 것이다. 통상적으로 가장 중요한 비중을 차지한 시술을 주시술로 결정하여 청구를 한다. 단, 다음과 같은 경우에는 예외 기준을 확인하여 처방에 주의해야 한다.

\section{1) 양측 간내담관 배액술을 시행하는 경우}

우측 간내담관과 좌측 간내담관으로 두 개의 스텐트를 넣었을 때 두 시술 모두 의사 행위료가 인정되며 하나는 $100 \%$, 다른 하나는 $50 \%$ 로 산정한다. 유일하게 행위료를 두 번 처방할 수 있는 시술이다. 이때 스텐트는 사용한 개수만큼 모두 청구한다. 양측 간내담관을 제외한 그 외의 경우에는 하나의 시술만 청구할 수 있다. 담관과 췌관에 각각 스텐트를 삽입하였다고 해도 하나의 시술만 청구해야 한다.

2) 동일 입원 기간 중 순차적으로 내시경적 비담관배액술 (endoscopic nasobiliary drainage, ENBD)과 내시경적 역행담관배액술(endoscopic retrograde biliary drainage, $\mathrm{ERBD})$ 을 각각 시행한 경우

동일 입원 기간 중 환자의 상태에 따라 순차적으로 $\mathrm{ENBD}$ 와 $\mathrm{ERBD}$ 를 각각 실시한 경우 시술별 소정 점수의 $100 \%$ 를 각각 산정하고, 시술 종류를 불문하고 최대 3 회 이내로 산정한다. 같은 입원 기간 동안 $\mathrm{ENBD}$ 또는 $\mathrm{ERBD}$ 횟수가 3 회가 넘는 경우는 사례별로 보험이 인정되므로, 이런 경우에는 3 회를 초과하여 시행한 합리적인 이유를 설명하는 의무 기록이 있어야한다.

3) ERCP-EST 시 선택적 삽관 및 예비절개술에 실패한 경우 2015년 10월 21일부터 심평원 진료심사평가위원회에 심사 사례로 정해진 내용이 2020년 1월 1일부터 고시로 신설되어, ERCP-EST 시 선택적 삽관 및 예비절개술에 실패한 경우에는 EST 소정 점수의 $50 \%$ 로 산정할 수 있다.

Table 1. 행위 급여·비급여 목록 및 급여 상대가치점수

\begin{tabular}{|c|c|c|c|}
\hline 분류번호 & 코드 & 분류 & 점수 \\
\hline \multirow[t]{9}{*}{ 자-776 } & & 역행성 담췌관 내시경 수술 & \\
\hline & Q7761 & 가. 유두괄약근절개술 & $7,294.49$ \\
\hline & Q7762 & 나. 담(췌)관배액술 & $7,910.00$ \\
\hline & Q7763 & 다. 내시경적 담(췌)관 협착확장술 & $6,858.67$ \\
\hline & & 라. 담(췌)석제거술 & \\
\hline & Q7764 & (1) 바스켓 또는 풍선카테터 이용, 기계적 쇄석술 시 & $8,299.76$ \\
\hline & Q7765 & (2) 전기수압쇄석술 시 & $7,028.09$ \\
\hline & Q7766 & 마. 용종 및 종양제거술 & $8,722.09$ \\
\hline & Q7767 & 바. 이물질제거술 & $7,405.46$ \\
\hline
\end{tabular}




\section{4) 치료 기간 중 수회 실시한 담석제거술 수가 산정 방법}

입원 기간 중 담석제거술을 반복하는 경우 시술별 소정 점수의 $100 \%$ 를 각각 산정하고, 간외담관 결석인 경우 최대 3 회(300\%) 이내로 산정하고 간내담관 결석인 경우 최대 5 회(500\%) 이내로 산정한다. 다만, 담석제거술 전에 별도로 시행한 담관배액술은 산정횟수에 포함하지 않는다.

\section{2. 재료비}

\section{1) Cannulation catheter}

이전에는 재사용 catheter를 반복 사용하는 것으로 산정되어 상대가치점수 재료비에 포함되었고, 일회용 catheter는 보상받을 수 없었다. 2019년 1월 1일부터는 환자 안전 및 감염 예방을 위해 일회용 catheter 사용이 인정되어, 모든 ERCP 시술에 일회용 catheter 비용이 인상 반영되었고 상대가치가 상승하게 되었다. 상대가치에 catheter 가격이 포함되어 있으므로 별도 산정할 수 없으며, 일회용 catheter로 보상되고 있어 재사용 catheter는 사용하지 않기를 권고한다.

\section{2) 유도철사(guidewire)}

유도철사는 별도 신청이 가능하며 현재 개수에 대한 고시 규정은 없으나 시술 기록지에 사용 개수와 사유를 명확히 남기는 것이 필요하다

\section{3) Papillotome과 needle knife를 모두 사용한 경우}

Papillotome과 needle knife는 정액수가항목에 절개도군에 포함되어 있어 papillotome만 급여 인정되고 needle knife는 청구할 수 없다. Papillotome 없이 needle knife만 사용한 경우에는 needle knife를 청구할 수 있다.

4) 비금속 담췌관 스텐트 삽입을 위한 전달 재료(delivery system과 pushing catheter)

2019년 10월 1일부터 비금속 담췌관 스텐트를 삽입하기 위해 사용하는 전달 재료(delivery system과 pushing catheter)는 모두 별도 산정할 수 있다.

\section{5) 동시 사용한 basket catheter와 balloon catheter}

결석을 완전 제거할 수 있는 상호보완적인 치료 재료인 점 등을 감안하여 동시 사용 시에는 각각 인정한다.

\section{6) 악성 담도협착에서 금속스텐트}

2015년 9월 1일부터 악성 종양에 의해 담관협착이 있는 경우 담도금속스텐트를 사용할 수 있는 담도금속스텐트의 개수 제한이 없어졌다.

\section{7) 양성 담도협착에서 금속스텐트}

담도의 협착, 출혈, 누출, 누공 및 천공에서 풍선확장술, 수술, 기타 기존 치료에 효과가 없거나 시행이 어려운 경우 제거가 가능한 피복형 금속스텐트가 2020년 1월 1일부터 보험으로 인정되었다. 특히, 담도의 양성협착에 금속스텐트를 사용하려면 이전에 담도확장술이나 담도배액술 등을 시행해야 하며, 양성협착에 확장효과가 없을 때 피복형 금속스텐트를 사용할 수 있다. 사용 후에는 판독지에 사유를 정확하게 명시하는 것이 필요하다.

\section{8) 풍선확장카테터(balloon dilatation catheter)}

비관혈적(내시경적 또는 경피적) 담관협착확장술 시 사용한 풍선확장카테터는 담관협착 시 협착된 담관을 확장시킬 목적으로 사용하는 필수 재료로서 별도 인정된다. 다만, 이때 풍선확장을 위해 사용한 balloon inflation device는 별도 산정할 수없다.

9) 결석 제거용 basket의 급여 기준

급여 개수는 1 개이나 쇄석술을 시행하는 경우, $1 \mathrm{~cm}$ 이상의 거대결석이 있는 경우, 5 개 이상의 다발성 결석을 제거하는 경우 결석 제거용 바스켓의 추가 사용을 인정한다. 2020년 10월 1 일부터 $2 \mathrm{~cm}$ 이상의 거대결석에서 $1 \mathrm{~cm}$ 이상으로 기준이 완화되었다. 추가 사용한 경우에는 판독지에 그 사유를 정확하게 명시하는 것이 필요하다.

\section{0) 용종 및 종양제거술}

내시경적 유두부 절제술을 시행한 경우 주시술인 유두부 절제술을 $100 \%$ 로 산정한다. 사용한 올가미(snare)는 별도 산정하고 담관과 췌관에 삽입한 스텐트 개수만큼 청구한다. 그러나 병변을 띄우기 위해 사용하는 인젝터는 산정 불가능하고 지혈을 예방하기 위한 클립도 인정되지 않는다.

11) 경피경간담도경(percutaneous tranhepatic cholangioscopy, PTCS) 카테터

2019년 1월 1일부터 경피경간 통로의 확장을 위해서 1회용 
PTCS 카테터는 1회 시술 시 2개 이내에서 실사용량으로 청구할 수 있다.

\section{결 론}

$\mathrm{ERCP}$ 를 시작하는 의사는 보험고시 기준을 숙지하고 정확하게 보험청구를 하여 누락되거나 부당 청구하는 일이 없어야 한다. 그리고 대한췌장담도학회 보험위원회에서 보내주는 보험고시도 참고하여 새로 바뀐 내용에 대해 잘 알고 적용해야 한다. 불합리한 삭감을 당하지 않기 위해서는 평소에 중요한 사진들을 찍어서 근거로 남기고, 기록지에 자세한 내용과 사유도 명시하는 것이 필요하다. 마지막으로, 의사나 간호사가 처방을 하고 나서는 이중 확인하여 제대로 청구하였는지 검증하는 과정이 필요하다.

\section{요 약}

내시경역행담췌관조영술을 시행함에 있어 의사들은 기본적 으로 보험고시를 잘 알고 있어야 한다. 행위료와 재료비로 나누어서 각각 청구하게 되며 보험고시에 따라 청구해야 나중에
불이익을 받지 않는다. 내시경역행담췌관조영술에 대한 보험고시도 종종 바뀌기 때문에 변경된 내용을 잘 숙지하고 적용해야 한다. 시술 중에는 적절하게 사진을 근거로 남겨야 하고, 시술 후에는 판독지에 시술 과정과 사용한 재료에 대해 기록을 잘 남기는 것이 중요하다. 시술 후에는 처방에 대해 이중 확인하여 보험청구를 제대로 하였는지 검증해야 한다.

국문 색인: 보험청구, 내시경역행담췌관조영술, 행위료, 재료비

\section{Conflicts of Interest}

The author has no conflicts to disclose.

\section{REFERENCES}

1. Park JM, Kang CD, Lee JC, Hwang JH, Kim J. Recent 5-year trend of endoscopic retrograde cholangiography in Korea using national health insurance review and assessment service open data. Gut Liver 2020;14:833-841.

2. Ahn DW, Han JH, Kim HJ, et al. Practice of endoscopic retrograde cholangiopancreatography in Korea: results from a national survey. Korean J Pancreas Biliary Tract 2019;24:21-30. 